\title{
Mead Acid
}

National Cancer Institute

\section{Source}

National Cancer Institute. Mead Acid. NCI Thesaurus. Code C68390.

A polyunsaturated long-chain fatty acid with a 20-carbon backbone and 3 double bonds, originating from the 9th, 12th and 15th positions from the methyl end, with all bonds in the cis- configuration. 